\title{
Apoptosis-associated biomarkers in tuberculosis: promising for diagnosis and prognosis prediction
}

\author{
Chin-Chung Shu ${ }^{1,2}$, Ming-Fang Wu ${ }^{4,5}$, Chia-Lin Hsu ${ }^{3}$, Chun-Ta Huang ${ }^{1,2}$, Jann-Yuan Wang ${ }^{3}$, Shie-Liang Hsieh ${ }^{4,5}$, \\ Chong-Jen Yu ${ }^{3}$, Li-Na Lee ${ }^{3,6}$ and Pan-Chyr Yang ${ }^{3}$
}

\begin{abstract}
Background: Apoptosis-associated biomarkers are rarely studied, especially their role in predicting the development of tuberculosis (TB) from latent TB infection and in prognostication.

Methods: Patients with TB and interferon-gamma release assay (IGRA)-positive and IGRA-negative family contacts were evaluated to analyze changes in apoptosis-associated serum biomarkers, which included decoy receptor 3 (DCR3), prostaglandin 2 (PGE2), and lipoxin. The prognostic implications of these serum biomarkers were also analyzed.

Results: One hundred TB patients and 92 IGRA-negative and 91 IGRA-positive family contacts were recruited. The DCR3 and PGE2 levels decreased from the IGRA-negative group to the IGRA-positive group, and peaked in the TB group. Lipoxin decreased to trough in the TB group. The three apoptosis serum markers and age were independent factors discriminating active TB from latent TB infection. In active TB, older age, co-morbidity, and higher serum DcR3 and monocyte chemotactic protein (MCP)-1 were independently associated with poorer six-month survival.

Conclusion: Apoptosis-associated serum biomarkers change along with the status of Mycobacterium tuberculosis infection. In close contacts with positive IGRA, high DCR3 and PGE2 and low lipoxin may increase the probability of active TB. Older age, co-morbidity, and high DcR3 and MCP-1 levels might be important prognostic factors that warrant further investigation.
\end{abstract}

Keywords: Apoptosis, Decoy receptor 3, Latent tuberculosis infection, Lipoxin, Prostaglandin E2, Tuberculosis

\section{Background}

Tuberculosis (TB) remains one of the most important infectious diseases worldwide. According to estimates of the World Health Organization (WHO), 3 hundred million people were infected by Mycobacterium tuberculosis and 30 million people died of TB from 2001 to 2010 [1,2]. In Taiwan, the incidence of TB remains high (58 per 100,000 population in 2009) [3]. To prevent further transmissions, early diagnosis and timely treatment are the most important strategies $[4,5]$.

Patients infected with $M$. tuberculosis will develop latent TB infection (LTBI), a major source of active TB [6]. Previous studies show that about $10 \%$ of LTBI

\footnotetext{
* Correspondence: jywang@ntu.edu.tw

${ }^{3}$ Department of Internal Medicine, National Taiwan University Hospital, \# 7 , Chung-Shan South Road, Taipei 100, Taiwan

Full list of author information is available at the end of the article
}

patients will develop the active disease and this risk is even higher in immuno-compromised hosts $[7,8]$. Nowadays, LTBI is detected by tuberculin skin test and by interferon-gamma release assay (IGRA), which measures T-cell response against tuberculous bacilli-specific antigen [9-11]. In particular, IGRA is reportedly more accurate in diagnosing LTBI and as an indicator of progression to active TB [12]. However, factors predicting the development of active TB from LTBI remain ineffective. Active TB is still identified mainly by traditional chest imaging and mycobacteriologic study.

In the pathogenesis of $\mathrm{TB}$, macrophages are the firstline of defense as the TB bacilli enter the airways [13]. Phagocytosis of the bacilli is then performed by phagocytic antigen-presenting cells in the lungs. However, $M$. tuberculosis has several mechanisms for persisting in human tissues [14-16]. For instance, necrosis of $M$. 
tuberculosis-infected macrophages as the dominant form of cell death instead of apoptosis $[15,17]$ prevents the removal of intracellular bacilli and the more efficient induction of inflammation [18].

Apoptosis-associated markers, including Decoy receptor3 (DcR-3), lipoxin, and prostaglandin E2 (PGE2) have rarely been investigated for discriminating active TB from LTBI in clinical practice. Among them, DcR3 is a receptor of the tumor necrosis factor (TNF) receptor super-family, existing as a soluble receptor for Fas ligand, a well-known marker in the extrinsic pathway of apoptosis, and is considered an immuno-modulator [19]. The latter two lipid markers antagonize macrophage apoptosis in an animal model when infected with $M$. tuberculosis $[17,20]$. Thus, this prospective study enrolled active TB cases and IGRApositive and IGRA-negative family contacts and compared serum apoptosis-associated markers to identify potentially discriminative diagnostic and prognostic factors.

\section{Methods}

\section{Enrolment of patients and contacts}

This prospective study was conducted in a tertiary-care referral center in northern Taiwan and its branch, a local teaching hospital in southern Taiwan. The Research Ethics Committee of National Taiwan University Hospital approved the study (No. 9561707008). From January 2009 to June 2011, adult patients (age $>20$ years) with culture- or histology-confirmed active TB were prospectively identified [5]. After providing informed consent, they received peripheral blood sampling before (TB at diagnosis) and one month after anti-TB treatment (TB under treatment) for measurement of serum biomarker levels.

Family contacts with known results of an interferongamma release assay (IGRA)-T-SPOT.TB (Oxford Immunotech Ltd, Oxford, UK) were also enrolled. Family contacts with negative T-SPOT.TB were considered the noninfection group whereas family contacts with positive TSPOT.TB were considered the LTBI group. The contacts received chest radiography and mycobacteriologic study (acid-fast smear and mycobacterial culture) from 3 sputum samples to exclude the possibility of active TB [5,21].

Patients and contacts with human immunodeficiency virus infection and those with bleeding tendency were excluded. Contacts with symptoms compatible with acute infection were also excluded.

\section{Measurements of biomarkers}

Assays for apoptosis-associated markers, including lipid markers (lipoxin and prostaglandin E [PGE]-2) and decoy receptor (DcR)-3, cytokines (interleukin [IL]-6, IL-10, tumor necrosis factor [TNF]-alpha, and interferon [IFN]-gamma), chemokines (monocyte chemotactic protein $[\mathrm{MCP}]-1$, macrophage inflammatory protein [MIP]1alpha, and MIP-1beta) were performed using serum samples in one batch. All samples were performed in a random order by a technician blinded to the clinical diagnosis. The Bioplex Multiplex Suspension Array System (Bio-Rad Laboratories Taiwan Ltd.) [22] was used for all chemokines and cytokines, while the ELISA method was used for lipoxin (Biosource, California, US), PGE2, and DcR3 (R\&D Systems Europe, Abingdon, UK).

The lower limits of detection for IL-6, IL-10, IFNgamma, TNF-alpha, MCP-1, MIP-1alpha, MIP-1beta, DcR3, lipoxin and PGE2 were 1.23, 1.81, 1.8, 4.72, 1.61, $1.4,1.4,93.7,780$, and $7.8 \mathrm{pg} / \mathrm{ml}$, respectively. If serum levels of a sample were below the detection range, it was noted as half of the lower limit, i.e. $0.615,0.905,0.9,2.36$, $0.805,0.7,0.7,46.85,390$, and $3.9 \mathrm{pg} / \mathrm{ml}$, respectively.

\section{Data collection}

Clinical data, including age, sex, underlying comorbidities, history of pulmonary TB, laboratory data, and results of acid-fast smear, mycobacterial culture, and drug susceptibility test, as well as anti-TB treatment course and outcomes were all recorded in a standardized case report form. Chest imaging was reviewed and noted as in a previous study [23]. The TB patients were followed-up for at least six months after anti-TB treatment or until death or loss to follow-up.

\section{Statistical analysis}

Serum levels of biomarkers among TB patients and family contacts were compared. Inter-group differences were analyzed by independent sample $t$ test or one-way analysis of variance (ANOVA) for numerical variables, and by $c h i$-square test for categorical variables. Multivariate logistic regression analysis was used to identify factors associated with TB among TB patients and family contacts with LTBI. For TB patients, survival curves were generated using the Kaplan-Meier method and compared using the log-rank test. Cox proportional hazards regression analysis was used to identify factors associated with six-month survival.

In the stepwise variable selection procedure, all potential predictors were included. A two-sided $p<0.05$ was considered significant. The discriminative power of each biomarker for 1) active TB from LTBI and 2) mortality from survival in TB patients was analyzed using the receiver operating characteristic (ROC) curve and area under the curve (AUC). The optimal cut-off value, defined as the one with the least $(1 \text { - sensitivity })^{2}+(1 \text { - specificity })^{2}$, was used to calculate sensitivity and specificity [24]. All analyses were performed using the SPSS (Version 13.0, Chicago, IL).

\section{Results}

During the study period, 100 TB patients (TB at diagnosis group), 92 IGRA-negative (non-infection group), and 91 IGRA-positive (LTBI group) family contacts were 
enrolled. The TB patients were significantly older, with male predominance, and had higher proportion of prior TB history and underlying co-morbidity compared to the family contacts (Table 1). Among the $100 \mathrm{~TB}$ patients, 55 received follow-up blood sampling one month after antiTB treatment (TB under treatment group).

Between the non-infection and LTBI groups, there was no significant difference in serum levels of biomarkers except for MCP-1 (27.86 vs. $18.30 \mathrm{pg} / \mathrm{ml}, p=0.039)$. Between the LTBI and TB at diagnosis groups, IL-6 (2.7 vs. $64 \mathrm{pg} / \mathrm{ml}, p=0.018)$, MCP-1 (18.30 vs. 34.05, $p=0.043)$, DcR3 (0.64 vs. $3.97 \mathrm{ng} / \mathrm{ml}, p<0.001)$, and PGE2 (0.31 vs. $3.04, p=0.001)$ were significantly higher in the latter, whereas lipoxin (3.391 vs. $1.73, p=0.008)$ was significantly higher in the former. All cytokines, DcR3, lipoxin, and PGE2 levels were not significantly different between TB patients with malignancy and those without. Serum levels of these markers were also not significantly different between the TB at diagnosis and TB under treatment groups (see online Additional file 1).

Among the four groups (i.e., non-infection group, LTBI group, TB at diagnosis group, and TB under treatment group), inflammatory cytokines, including IL-6, TNF-alpha, and IFN-gamma decreased from the noninfection group to the LTBI group, and then increased in the TB patients (Figure 1A). In contrast, IL-10 showed a continuous decreasing trend (statistically not significant). Regarding chemokines, the trend of MCP-1 was comparable to those of inflammatory cytokines but the trends of MIP-1alpha and MIP-1beta increased gradually from the non-infection group to the LTBI group to the TB group (Figure 1B). As for apoptosis-associated markers, the trends of DcR3 and PGE2 were similar to those of inflammatory cytokines but lipoxin had an opposite trend (Figure 1C).

Multivariate logistic regression analysis for the LTBI and $\mathrm{TB}$ at diagnosis groups revealed that age and serum DcR3, PGE2, and lipoxin levels were independently associated with active TB (Table 2). The results were similar in the sub-population analysis focusing on subjects without malignancy $(p=0.007, p<0.001, p=0.004, p=0.017$, respectively). The AUC under the ROC curves of age, DcR3, PGE2, and lipoxin was 0.819, 0.932, 0.859, and 0.743 , respectively (Figure 2 ). The optimal cut-off values were 67 years old (sensitivity $71 \%$; specificity $87 \%$ ), 1.14 $\mathrm{ng} / \mathrm{ml}$ (sensitivity $87 \%$; specificity $87 \%$ ), $0.35 \mathrm{ng} / \mathrm{ml}$ (sensitivity $81 \%$; specificity $79 \%$ ), and $1.82 \mathrm{ng} / \mathrm{ml}$ (sensitivity $65 \%$; specificity $82 \%$ ), respectively. A combination of three biomarkers was used to predict the probability of active TB disease (Table 3) and the presence of any two provided a sensitivity of $99 \%$ and specificity of $72 \%$.

Among the 100 TB patients, 21 (21\%) died (of any cause) during the study. Comparing the clinical characteristics, survivors were younger and less likely to have underlying co-morbidity. Non-survivors had higher serum MCP-1 ( $p=0.012)$ and DcR3 ( $p=0.078)$ levels (Table 4).

Using the optimal cut-off values determined by ROC curve analysis, the Kaplan-Meier survival curves of TB patients according to serum MCP-1 (>28.72 vs. $\leq 28.72$ $\mathrm{pg} / \mathrm{ml})$ and DcR3 (>2.67 vs. $\leq 2.67 \mathrm{ng} / \mathrm{ml})$ levels were plotted (Figure 3 ). The $p$ values compared by log-rank test were 0.002 and 0.004 , respectively. Multivariate Cox regression analysis revealed that age, co-morbidity, and serum MCP-1 and DcR3 levels were independent factors predicting six-month survival (Table 5).

\section{Discussion}

Using four groups (i.e., non-infection group, LTBI group, $\mathrm{TB}$ at diagnosis group, and TB under treatment group) of data that represent the different stages in the development of active TB disease, the present study reveals that apoptosis-associated biomarkers change significantly. Levels of DcR3 and PGE2 are elevated but lipoxin is decreased when patients have active TB compared to latent infection. Combinations of the three biomarkers and age may be useful and promising tools in clinical practice to predict the development of active TB among family contacts with LTBI. As for TB patients, age and underlying co-morbidity, and serum DcR3 and MCP-1 levels at the time of diagnosis are significantly associated with six-month survival.

Table 1 Clinical characteristics of patients with tuberculosis (TB) and family contacts by responses to interferongamma release assay

\begin{tabular}{lllll}
\hline & IGRA-negative contacts $\mathbf{n}=\mathbf{9 2}$ & IGRA-positive contacts $\mathbf{n}=\mathbf{9 1}$ & TB patients $\mathbf{n = 1 0 0}$ & $\boldsymbol{p}$ value \\
\hline Age (years) & $44.6[16.9]$ & $51.3[15.6]$ & $70.3[16.2]$ & $62(62 \%)$ \\
Male sex & $32(35 \%)$ & $33(36 \%)$ & $10(10 \%)$ & $<0.001$ \\
History of TB & 0 & 0 & $39(39 \%)$ & $<0.001$ \\
Co-morbidity & $3(3 \%)$ & $7(8 \%)$ & $30(30 \%)$ & $<0.001$ \\
Diabetes mellitus & $2(2 \%)$ & $5(6 \%)$ & $15(15 \%)$ & $<0.001$ \\
Malignancy & $1(1 \%)$ & $3(3 \%)$ & $2(2 \%)$ & $<0.001$ \\
Liver cirrhosis & 0 & 0 & & 0.001 \\
\hline
\end{tabular}

Data are no. (\%) or mean [standard deviation]. 


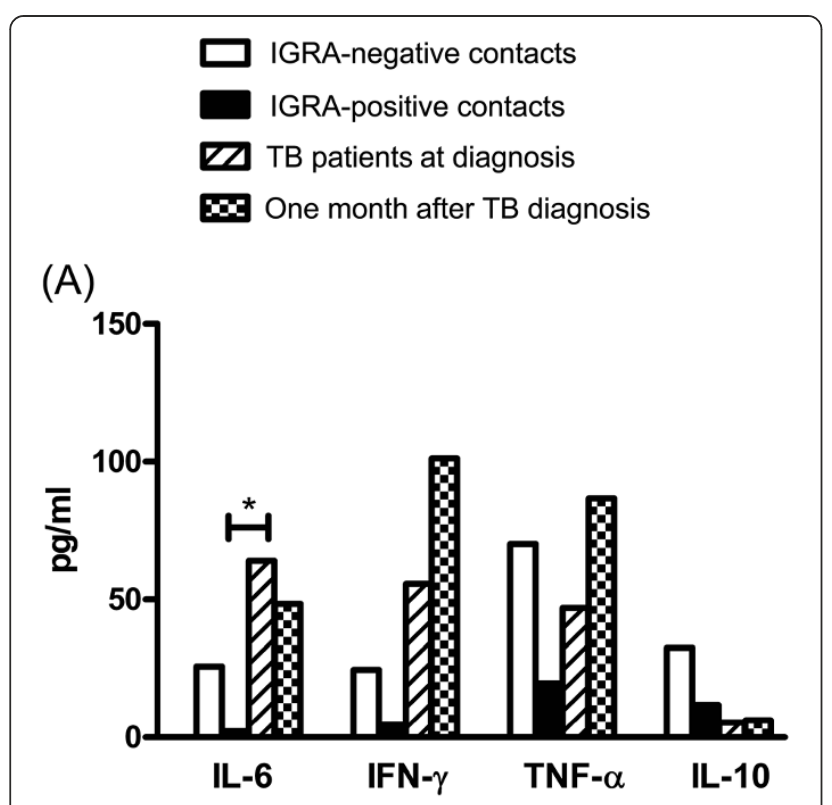

(B)

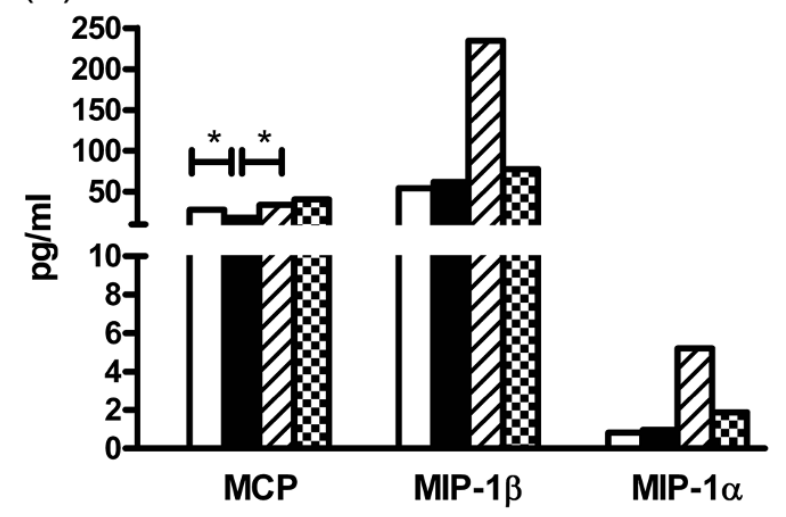

(C)

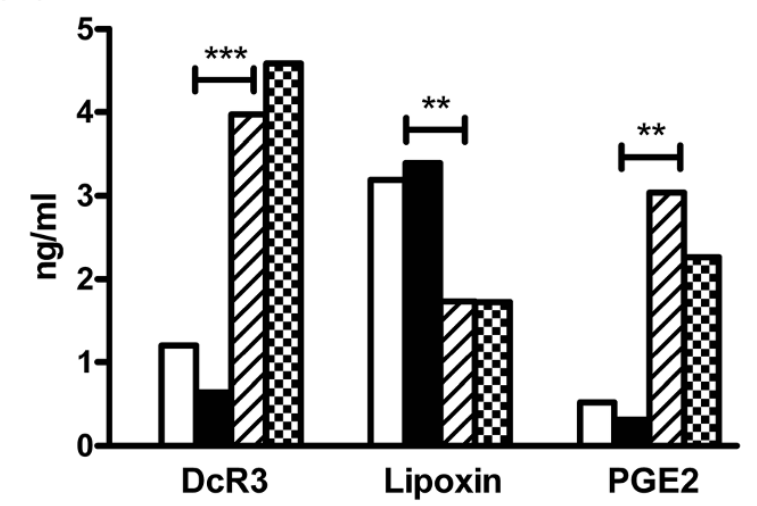

Figure 1 Histogram shows serum levels of (A) cytokines, (B) chemokines, and $(C)$ apoptosis-associated markers among family contacts and patient with tuberculosis. Dx, diagnosis; $T x$, treatment; ${ }^{*} p<0.050$; ${ }^{* *} p<0.010$; ${ }^{* *} p<0.001$.
Table 2 Factors significantly associated with tuberculosis (TB) in multivariate logistic regression analysis among contacts with latent TB infection and TB patients

\begin{tabular}{lll}
\hline Characteristics & $\boldsymbol{p}$ value & OR (95\% C.I.) \\
\hline Age, per 1 year increment & 0.003 & $1.07(1.02-1.11)$ \\
DcR 3, per $1 \mathrm{ng} / \mathrm{mL}$ increment & $<0.001$ & $11.91(4.03-35.17)$ \\
Lipoxin, per $1 \mathrm{ng} / \mathrm{mL}$ increment & $<0.001$ & $0.39(0.23-0.66)$ \\
PGE2, per $1 \mathrm{ng} / \mathrm{mL}$ increment & $<0.001$ & $21.71(4.66-101.28)$ \\
\hline
\end{tabular}

Abbreviations: TB, tuberculosis; DCR 3, decoy receptor 3; PGE2, prostaglandin E2.

During latent infection, M. tuberculosis has several mechanisms to protect itself from human immunity [14-16]. One is the suppression of apoptosis of infected macrophages because this will result in the removal of intracellular bacilli and induction of inflammation $[18,25]$. M. tuberculosis also promotes its replication by inhibiting the apoptosis of infected macrophages [18]. Macrophage death toward necrosis instead of apoptosis is therefore a considerably advantageous evasion mechanism of $M$. tuberculosis [26].

Later, there are overwhelming systemic inflammatory responses when active disease develops. Thus, levels of inflammatory cytokines decrease when subjects progress from non-infection status to latent infection, and peak in the active TB disease status. Although DcR3 and PGE2 levels have a similar trend, DcR3 may be a downstream (passive) responder to inflammation-related apoptosis and enhance the signal pathway. PGE2 plays a relatively active role in the upstream of apoptosis $[19,27,28]$. In addition,

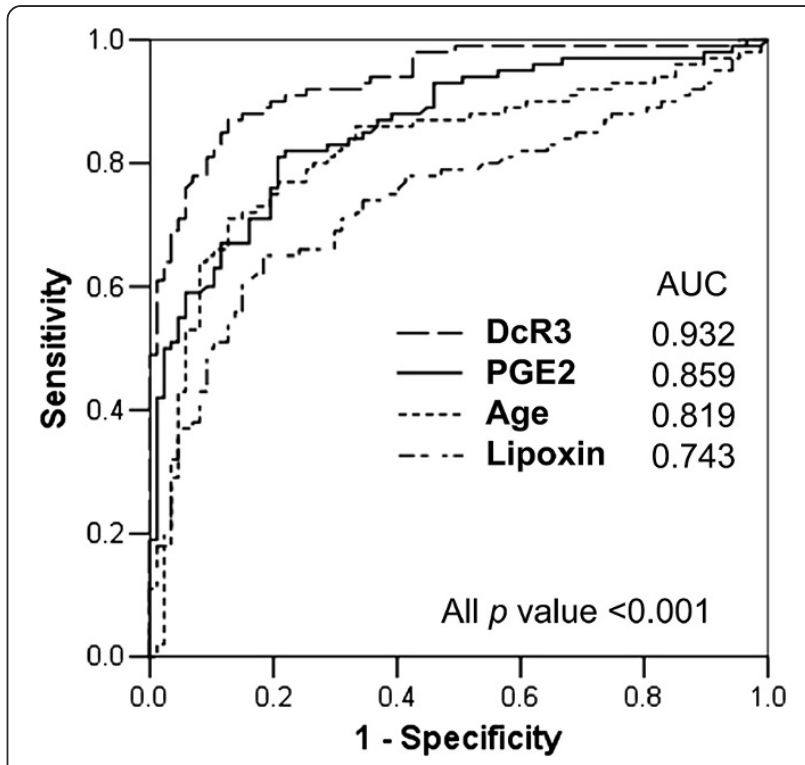

Figure 2 Receiver operating characteristic curves of factors independently associated with tuberculosis among interferongamma release assay (IGRA)-positive contacts and patients with tuberculosis. 
Table 3 Predicting the presence of tuberculosis (TB) by biomarkers

\begin{tabular}{lllllll}
\hline Conditions & No. of matched subjects & TB patients & Sensitivity & Specificity & Positive predictive value & Negative predictive value \\
\hline All & 59 & 51 & $51 \%$ & $92 \%$ & $86 \%$ & $65 \%$ \\
Any two & 127 & 99 & $99 \%$ & $72 \%$ & $78 \%$ & $99 \%$ \\
Anyone & 140 & 99 & $99 \%$ & $59 \%$ & $71 \%$ & $98 \%$ \\
\hline
\end{tabular}

The three clinical factors included were Decoy receptor 3 (DcR3) $>1.14 \mathrm{ng} / \mathrm{mL}$, prostaglandin E2 (PGE2) $>0.35 \mathrm{ng} / \mathrm{mL}$, and lipoxin $<1.82 \mathrm{ng} / \mathrm{mL}$.

Table 4 Clinical characteristics, laboratory results, radiologic findings and disease extent among patients with tuberculosis (TB)

\begin{tabular}{|c|c|c|c|}
\hline & Survivors $n=79$ & Non-survivors $n=21$ & $p$ value \\
\hline Age (years) & $68.2[16.9]$ & $78.3[9.6]$ & 0.010 \\
\hline Male sex & $48(61 \%)$ & $14(67 \%)$ & 0.620 \\
\hline History of TB & $6(8 \%)$ & $4(19 \%)$ & 0.120 \\
\hline Co-morbidity & 27 (34\%) & 12 (57\%) & 0.055 \\
\hline Diabetes mellitus & $24(30 \%)$ & $6(29 \%)$ & 0.872 \\
\hline Malignancy & $6(8 \%)$ & $9(43 \%)$ & $<0.001$ \\
\hline Liver cirrhosis & 0 & $2(10 \%)$ & 0.006 \\
\hline Diagnosis evidence & & & 0.051 \\
\hline Culture positive & $79(100 \%)$ & $20(95 \%)$ & \\
\hline Pathology positive & 0 & $1(5 \%)$ & \\
\hline \multicolumn{4}{|l|}{ Mtb resistance } \\
\hline INH resistance & $8(10 \%)$ & 0 & 0.128 \\
\hline RIF resistance & 0 & $1(5 \%)$ & 0.051 \\
\hline Sputum AFS-positive & $52(66 \%)$ & $11(52 \%)$ & 0.257 \\
\hline \multicolumn{4}{|l|}{ Radiographic pattern } \\
\hline Upper lung lesion & $53(67 \%)$ & $13(62 \%)$ & 0.656 \\
\hline Cavitation & $11(14 \%)$ & $1(5 \%)$ & 0.251 \\
\hline Disease extent & & & 0.653 \\
\hline Pulmonary & 64 (81\%) & $18(86 \%)$ & \\
\hline Extra-pulmonary only & $3(4 \%)$ & 0 & \\
\hline Mixed & $12(15 \%)$ & $3(14 \%)$ & \\
\hline \multicolumn{4}{|l|}{ Blood tests } \\
\hline Leukocyte, $(/ \mu \mathrm{L})$ & 9609 [4880] & 10297 [4207] & 0.542 \\
\hline Interleukin-6 & $54.9[257.3]$ & $98.2[196.6]$ & 0.408 \\
\hline Interleukin-10 & $5.6[23.1]$ & $4.7[12.2]$ & 0.814 \\
\hline Interferon-gamma & $66.3[472.7]$ & 15.4 [38.9] & 0.347 \\
\hline TNF-alpha & $50.8[375.5]$ & $32.7[123.7]$ & 0.720 \\
\hline MCP-1 & $25.0[50.1]$ & $68.2[116.1]$ & 0.012 \\
\hline MIP-1alpha & $6.1[29.8]$ & $1.8[2.6]$ & 0.210 \\
\hline MIP-1beta & 245.4 [1274.7] & 193.3 [366.2] & 0.752 \\
\hline Decoy receptor 3 & $3.6[3.8]$ & $5.3[3.7]$ & 0.078 \\
\hline Lipoxin & $1.7[1.5]$ & $1.7[1.2]$ & 0.939 \\
\hline Prostaglandin E2 & $2.9[8.1]$ & $3.4[7.0]$ & 0.793 \\
\hline
\end{tabular}

Data are no. (\%) or mean [standard deviation].

Abbreviations: MCP, monocyte chemotactic protein; MIP, macrophage inflammatory protein; TNF, tumor necrosis factor. the trend of lipoxin shows its function of antagonizing PGE2 in apoptosis control.

After M. tuberculosis infection, macrophages are activated locally and chemokines increase, leading to a gradual increase in serum MIP level from non-infection and

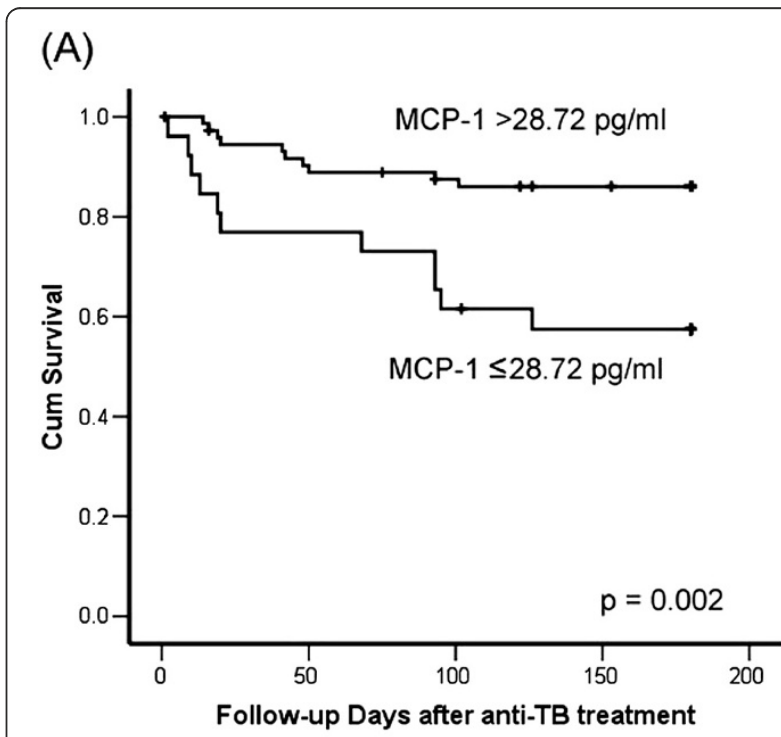

(B)

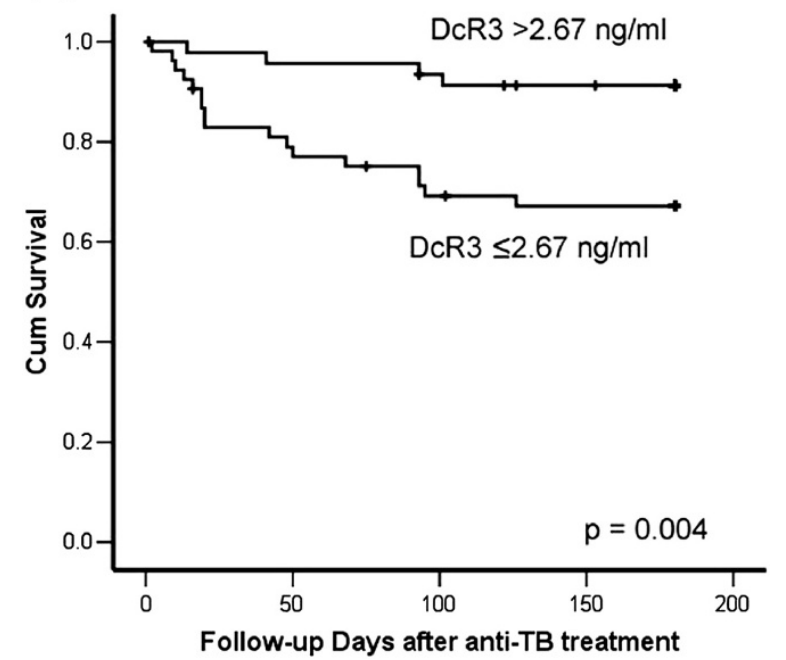

Figure 3 Survival curves plotted using the Kaplan-Meier method for patients with tuberculosis and different serum levels of (A) MCP-1 and (B) DcR3. 
Table 5 Factors independently associated with worse sixmonth survival in patients with tuberculosis, by Cox proportional hazards regression analysis

\begin{tabular}{lll}
\hline Characteristics & $\boldsymbol{p}$ value & HR (95\% C.I.) \\
\hline Age, per 1 year increment & 0.008 & $1.072(1.018-1.129)$ \\
Co-morbidity & 0.007 & $3.856(1.450-10.256)$ \\
DCR 3, per $1 \mathrm{ng} / \mathrm{mL}$ increment & 0.046 & $1.089(1.001-1.183)$ \\
MCP, per $1 \mathrm{pg} / \mathrm{mL}$ increment & $<0.001$ & $1.008(1.004-1.013)$ \\
PGE2, per $1 \mathrm{ng} / \mathrm{mL}$ increment & 0.063 & $1.059(0.997-1.125)$ \\
\hline
\end{tabular}

Abbreviations: DcR 3, Decoy receptor 3; MCP, monocyte chemotactic protein; PGE2, Prostaglandin E2.

LTBI to active TB. However, MCP-1 recruits monocytes and $\mathrm{T}$ lymphocytes later during the granulomatous response [29] and may not significantly increase during LTBI. This explains the similar trend of change as inflammatory cytokines.

Apoptosis-associated biomarkers, rather than inflammatory cytokines, are independent factors in predicting active TB. They are of practical importance yet remain largely unexplored. This is probably because inflammatory cytokines may be influenced by multiple factors during inflammation, whereas apoptosis-associated biomarkers are much simpler in their pathways and have less influence. Although apoptosis-associated markers may be confounded by underlying co-morbidity, the association between these markers and active TB is probably independent of underlying co-morbidity, based on the results of the current analyses.

Among the apoptosis-associated biomarkers, DcR3 seems to be the most associated with immune cells $[19,28,30]$. It has the potential to discriminate between latent and active TB using the ROC curve analysis. From a public health consideration, a test with high sensitivity for predicting the development of active TB from LTBI is most useful in preventing delayed $\mathrm{TB}$ diagnosis and further transmission. If $99 \%$ of active TB cases can be identified by DcR3 $>1.14 \mathrm{ng} / \mathrm{ml}$ plus PGE2 $>0.35 \mathrm{ng} / \mathrm{ml}$, these will be useful as screening criteria.

The six-month survival of TB patients may be confounded by numerous factors and is difficult to predict simply based on characteristics at diagnosis. Many influential factors may be missed in the analysis. Nonetheless, the results imply that baseline health conditions and extent of immune response to TB have prognostic importance. DcR3 has been reported as an immuno-modulator that skews immune response into type II macrophages but also induces dendritic cell apoptosis [28,30]. Hence, it may be a promising indicator of overwhelming inflammatory response for destruction during active TB. As a potent recruiting signal for monocytes and $\mathrm{T}$ cells [31], higher serum MCP-1 level may imply more severe granulomatous inflammation [29]. This is the first time that MCP-1 level in TB patients is demonstrated as a promising tool for outcome prediction.

This study has some limitations. First, inter-group comparison is performed in different individuals and may be biased by individual variations. Disease processes other than TB, like cancer, may influence serum levels of biomarkers. Second, biomarker responses after in vitro stimulation are not assayed. Thus, it cannot be simply concluded that the measured levels of biomarkers in study subjects are solely due to immune response against $M$. tuberculosis. Third, the study was conducted in a tertiary referral center and a regional teaching hospital. The high prevalence of underlying co-morbidities in TB patients may change the serum levels of biomarkers and lead to a relatively high mortality rate. This limits the external generalization of the study results. Furthermore, due to the small number of follow-up samples, firm conclusions cannot be made for the biomarker levels after treatment.

\section{Conclusion}

In conclusion, apoptosis-associated markers significantly correlate with the status of $M$. tuberculosis infection. High DcR3 level, high PGE2 level, and low lipoxin level may be highly sensitive criteria for identifying active TB cases among contacts with LTBI. Prognosis is poorer in TB patients with older age, underlying co-morbidity, and high serum DcR3 and MCP-1 levels.

\section{Additional file}

Additional file 1: The details of serum markers in patients with tuberculosis and the family contacts.

\section{Competing interests}

All of the authors declare no financial, professional, or other personal interests of any nature or kind in any related product, service, and/or company.

\section{Authors' contribution}

LLN and WJY conceived the study. WJY, SCC, HCL and HCT were involved in the sample and clinical data collection. SCC, WJY, HCL, LLN and YPC participated in data analysis and in manuscript writing, together with WMF and HSL. YCJ and WJY were directors responsible for the study organization. All authors read and approved the final manuscript.

\section{Acknowledgements}

The authors thank the staff of the Eighth Core Lab of the Department of Medical Research of National Taiwan University Hospital for their technical support.

\section{Funding sources}

This study was supported by the National Science Council of Taiwan (grant NSC 100-2325-B-002-010) and the National Taiwan University Hospital (NTUH-101_N1949).

\section{Author details}

${ }^{1}$ Department of Traumatology, National Taiwan University Hospital, Taipei, Taiwan. ${ }^{2}$ Graduate Institute of Clinical Medicine, College of Medicine, National Taiwan University, Taipei, Taiwan. ${ }^{3}$ Department of Internal Medicine, 
National Taiwan University Hospital, \# 7, Chung-Shan South Road, Taipei 100, Taiwan. ${ }^{4}$ Institute of Microbiology and Immunology, National Yang-Ming University, Taipei, Taiwan. ${ }^{5}$ Institute of Clinical Medicine \& Infection and Immunity Center, National Yang-Ming University, Taipei, Taiwan.

${ }^{6}$ Department of Laboratory Medicine, National Taiwan University Hospital, Taipei, Taiwan

Received: 19 August 2012 Accepted: 24 January 2013

Published: 28 January 2013

\section{References}

1. World Health Organization: Global tuberculosis control: surveillance, planning, financing. Geneva, Switzerland: World Health Organization; 2008.

2. World Health Organization: Group at risk: WHO report on the tuberculosis epidemic. Geneva, Switzerland: World Health Organization; 1996.

3. Chang FY, Shih WY, Lin T, Chou JH, Chen YH, Liu DP, Yang CH, Chen CH, Yen CC, Wu HS, Wu PF, Cheng AH, Ke YF, Tien CF, Wu YH: CDC annual report 2011. Taipei: Centers of Disease Control, Department of Health, R.O.C. (Taiwan); 2011.

4. American Thoracic Society, CDC, and Infectious Diseases Society of America: Treatment of tuberculosis. MMWR Recomm Rep 2003, 52(RR-11):1-77.

5. Luh KT, Chiang CY, Lee JJ, Wang JY, Wang KF, Yu MC, Lee PI, Lee PH, Lin HH, Chiang IH, Chan PC, So R, Su WJ, Hung CC: Taiwan guidelines for TB diangosis and treatment. Taiwan (R.O.C.): Center for Disease Control, Executive Yuan; 2011.

6. Hopewell PC, Kato-maeda M: Tuberculosis. In Murray and Nadel's textbook of respiratory medicine. Volume 1. $5^{\text {th }}$ edition. Edited by Mason RJ, Broaddus VC, Martin T, King T, Schraufnagel D, Murray JF, Nadel JA: Elsevier Inc in Philadelphia, Pennsylvania, the United States of America; 2010:754-792.

7. Lundin AP, Adler AJ, Berlyne GM, Friedman EA: Tuberculosis in patients undergoing maintenance hemodialysis. Am J Med 1979, 67(4):597-602.

8. Jick SS, Lieberman ES, Rahman MU, Choi HK: Glucocorticoid use, other associated factors, and the risk of tuberculosis. Arthritis Rheum 2006, 55(1):19-26.

9. Wang L, Turner MO, Elwood RK, Schulzer M, FitzGerald JM: A meta-analysis of the effect of bacille calmette guerin vaccination on tuberculin skin test measurements. Thorax 2002, 57(9):804-809.

10. Pai M, Zwerling A, Menzies D: Systematic review: T-cell-based assays for the diagnosis of latent tuberculosis infection: an update. Ann Intern Med 2008, 149(3):177-184.

11. Chang KC, Leung CC: Systematic review of interferon-gamma release assays in tuberculosis: focus on likelihood ratios. Thorax 2010, 65(3):271-276.

12. Diel R, Loddenkemper R, Meywald-Walter K, Niemann S, Nienhaus A: Predictive value of a whole blood IFN-gamma assay for the development of active tuberculosis disease after recent infection with mycobacterium tuberculosis. Am J Respir Crit Care Med 2008, 177(10):1164-1170.

13. Jo EK: Mycobacterial interaction with innate receptors: TLRs, C-type lectins, and NLRs. Curr Opin Infect Dis 2008, 21(3):279-286.

14. Noss EH, Pai RK, Sellati TJ, Radolf JD, Belisle J, Golenbock DT, Boom WH, Harding CV: Toll-like receptor 2-dependent inhibition of macrophage class II MHC expression and antigen processing by 19-kDa lipoprotein of mycobacterium tuberculosis. J Immunol 2001, 167(2):910-918.

15. Chen M, Gan H, Remold HG: A mechanism of virulence: virulent mycobacterium tuberculosis strain H37Rv, but not attenuated H37Ra, causes significant mitochondrial inner membrane disruption in macrophages leading to necrosis. J Immunol 2006, 176(6):3707-3716

16. Jung SB, Yang CS, Lee JS, Shin AR, Jung SS, Son JW, Harding CV, Kim HJ, Park JK, Paik TH, et al: The mycobacterial 38-kilodalton glycolipoprotein antigen activates the mitogen-activated protein kinase pathway and release of proinflammatory cytokines through toll-like receptors 2 and 4 in human monocytes. Infect Immun 2006, 74(5):2686-2696

17. Torrado E, Robinson RT, Cooper AM: Cellular response to mycobacteria: balancing protection and pathology. Trends Immunol 2011, 32(2):66-72.

18. Blomgran R, Desvignes $L$, Briken V, Ernst JD: Mycobacterium tuberculosis inhibits neutrophil apoptosis, leading to delayed activation of naive CD4 T cells. Cell Host Microbe 2012, 11(1):81-90.

19. Lin WW, Hsieh SL: Decoy receptor 3: a pleiotropic immunomodulator and biomarker for inflammatory diseases, autoimmune diseases and cancer. Biochem Pharmacol 2011, 81(7):838-847.
20. Bafica A, Scanga CA, Serhan C, Machado F, White S, Sher A, Aliberti J: Host control of mycobacterium tuberculosis is regulated by 5 -lipoxygenasedependent lipoxin production. J Clin Invest 2005, 115(6):1601-1606.

21. Harries A: What is the additional yield from repeated sputum examinations by microscopy and culture? In Toman's Tuberculosis case detection, treatment and monitoring. Edited by Frieden TR. Geneva: World Health Organization; 2004:46-50.

22. Gauglitz GG, Finnerty CC, Herndon DN, Mlcak RP, Jeschke MG: Are serum cytokines early predictors for the outcome of burn patients with inhalation injuries who do not survive? Crit Care 2008, 12(3):R81.

23. Shu CC, Wang JT, Wang JY, Lee LN, Yu CJ: In-hospital outcome of patients with culture-confirmed tuberculous pleurisy: clinical impact of pulmonary involvement. BMC Infect Dis 2011, 11:46.

24. Shu CC, Lee LN, Wu MF, Lee CH, Wang JT, Wang JY, Yu CJ: Use of soluble triggering receptor expressed on myeloid cells-1 in non-tuberculous mycobacterial lung disease. Int J Tuberc Lung Dis 2011, 15(10):1415-1420.

25. Arcila ML, Sanchez MD, Ortiz B, Barrera LF, Garcia LF, Rojas M: Activation of apoptosis, but not necrosis, during mycobacterium tuberculosis infection correlated with decreased bacterial growth: role of TNF-alpha, IL-10, caspases and phospholipase A2. Cell Immunol 2007, 249(2):80-93.

26. Park JS, Tamayo MH, Gonzalez-Juarrero M, Orme IM, Ordway DJ: Virulent clinical isolates of mycobacterium tuberculosis grow rapidly and induce cellular necrosis but minimal apoptosis in murine macrophages. J Leukoc Biol 2006, 79(1):80-86.

27. Chen M, Divangahi M, Gan H, Shin DS, Hong S, Lee DM, Serhan CN, Behar SM, Remold HG: Lipid mediators in innate immunity against tuberculosis: opposing roles of PGE2 and LXA4 in the induction of macrophage death. J Exp Med 2008, 205(12):2791-2801.

28. You Rl, Chang YC, Chen PM, Wang WS, Hsu TL, Yang CY, Lee CT, Hsieh SL: Apoptosis of dendritic cells induced by decoy receptor 3 (DCR3). Blood 2008, 111(3):1480-1488.

29. Flores-Villanueva PO, Ruiz-Morales JA, Song CH, Flores LM, Jo EK, Montano M, Barnes PF, Selman M, Granados J: A functional promoter polymorphism in monocyte chemoattractant protein-1 is associated with increased susceptibility to pulmonary tuberculosis. J Exp Med 2005, 202(12):1649-1658.

30. Chang YC, Chen TC, Lee CT, Yang CY, Wang HW, Wang CC, Hsieh SL: Epigenetic control of MHC class II expression in tumor-associated macrophages by decoy receptor 3. Blood 2008, 111(10):5054-5063.

31. Premack BA, Schall TJ: Chemokine receptors: gateways to inflammation and infection. Nat Med 1996, 2(11):1174-1178.

doi:10.1186/1471-2334-13-45

Cite this article as: Shu et al: Apoptosis-associated biomarkers in tuberculosis: promising for diagnosis and prognosis prediction. $B M C$ Infectious Diseases 2013 13:45.

\section{Submit your next manuscript to BioMed Central and take full advantage of:}

- Convenient online submission

- Thorough peer review

- No space constraints or color figure charges

- Immediate publication on acceptance

- Inclusion in PubMed, CAS, Scopus and Google Scholar

- Research which is freely available for redistribution 